\title{
The Data Protection Act 1998 - What does it mean for pension schemes?
}

Received: 10th October, 2000

\section{François Barker}

is an associate in the Pensions Unit at Hammond Suddards Edge in London. He was previously Lecturer in Law at Nottingham Trent and Hull Universities, where he also completed a PhD. He joined Edge \& Ellison in Birmingham in 1995, and moved to the London office prior to the merger with Hammond Suddards. He is involved in all aspects of advising pension schemes, including data protection compliance. He is a regular conference speaker on pensions issues.

\begin{abstract}
This paper analyses the impact of the Data Protection Act 1998 on occupational pension schemes. The 1998 Act introduces a data protection regime which is more robust and likely to be more vigorously enforced than was the case under the Data Protection Act 1984. Trustees, as 'data controllers' under the new Act, will be primarily responsible for ensuring their schemes comply with the new legislation. This paper considers some practical pensions issues, examines how the 1998 Act will apply to them, and suggests how trustees can ensure they comply in practice with the new legislation.
\end{abstract}

Keywords: pensions; data protection; compliance; disclosure; consent; human rights

François Barker Hammond Suddards Edge, 7 Devonshire Square, Cutlers Gardens, London EC2M 4YH

Tel: +44 (0)20 7655 1000; Fax: +44 (0)20 7655 1001; e-mail: francois.barker@ hammondse.com

\section{Introduction}

The Data Protection Act 1998 ('DPA 1998') received Royal Assent on 16th July, 1998, and came into force on 1st March, 2000. It was brought onto the statute book to comply with EU Directive 95/46/EC, adopted on 24th October 1995 ('the Directive'). Its provenance, however, can be traced much further back, and there is a clear link between the DPA 1998 and the Human Rights Act 1998. ${ }^{1}$ The latter incorporated the European Convention for the Protection of Human Rights and Fundamental Freedoms ('the Human Rights Convention') into the domestic law of England, Wales and Northern Ireland on 2nd October, 2000. ${ }^{2}$
This paper considers some of the main pensions implications of the new legislation, and tries to assist with some practical compliance points. Although this paper focuses on the occupational context, many of the same principles and issues will arise in relation to other schemes.

\section{The significance of the DPA 1998}

Given that the previous regime under the Data Protection Act 1984 ('DPA 1984') was generally lightly enforced, and many pension schemes avoided compliance by not registering in the first place, ${ }^{3}$ it might be asked why the position is likely to be any different 
under the DPA 1998.

It is suggested that there are three principal reasons why pension scheme trustees should take the new legislation seriously. The first reason is that they are 'data controllers' under the DPA 1998 and, as such, are primarily responsible for ensuring that their schemes comply with the new requirements. The new Information Commissioner (previously the Data Protection Commissioner, and before that, Registrar), Elizabeth France, is ready to enforce the new legislation, ${ }^{4}$ with public funds at her disposal and a range of enforcement options and sanctions open to her. ${ }^{5}$

The second reason is that the link with the Human Rights Act 1998 could result in the DPA 1998 having a higher profile (at least in the short term) than it otherwise might have done. With human rights rather 'flavour of the month' at present, data protection issues could well be raised in the context of broader challenges based on the human rights legislation. ${ }^{6}$

The third reason is that there is a clear risk for trustees that the DPA 1998 will (alongside the Pensions Ombudsman, the Disclosure Regulations $1996,{ }^{7}$ and the common law rules on the disclosure of 'trust documents' $)^{8}$ become a further weapon in the armoury of the aggrieved member or beneficiary, seeking to obtain sensitive information or challenge a contentious decision. Data subjects' rights of access to their personal data are strengthened under the DPA 1998, ${ }^{9}$ and the Commissioner has already run publicity campaigns to raise public awareness of the new legislation. ${ }^{10}$

Trustees who are prepared for data subject access requests, and who have thought carefully about how — and whether - to store and use particular personal data, will probably find that both the requests, and the information they have to disclose as a result of them, pose fewer problems.

\section{Key definitions}

Certain key terms are used throughout the DPA 1998. Since these are critical to understanding the scope and functioning of the legislation, a brief explanation of each of these in the pensions context appears below:

- Personal data: is information from which a living individual can be identified. ${ }^{11}$ A name and address will usually suffice, as will another unique identifier, such as a National Insurance number. Pension scheme trustees will inevitably process significant quantities of personal data - principally about members, their spouses and dependants.

- Sensitive personal data: is personal data which falls within one or more 'delicate' categories. The most relevant categories in the pensions context will be 'physical or mental health or condition', and 'sexual life'. ${ }^{12}$ Medical evidence submitted by a scheme member to support an ill health retirement application will be sensitive personal data.

- Processing: covers anything and everything done in relation to personal data, from creating it, through holding, using, transferring and amending it, to destroying it. All data controllers will inevitably process personal data simply by holding it (or having it held or stored for them) before any other aspects of the definition are considered. ${ }^{13}$

- Data controller: is the person who (alone or with others) decides how any personal data are, or are to be, processed. ${ }^{14}$ In the pensions context, the trustees of an occupational 
arrangement will always be data controllers, as will the provider of a personal arrangement.

- Data processor: is a third party who processes personal data on behalf of the data controller. ${ }^{15}$ In the pensions context, this will include administrators and actuaries, lawyers, annuity providers and quite often (in the occupational context) sponsoring and participating employers.

- Data subject: is the individual who is the subject of personal data. ${ }^{16}$ In the pensions context, this will principally mean the members and other beneficiaries.

\section{Overview of the DPA 1998}

Like the DPA 1984, the compliance regime introduced by the DPA 1998 is still based on eight core 'data protection principles', although the first seven new principles contain more detail than in the DPA 1984, and the eighth principle in the DPA 1998 is completely new. ${ }^{17}$ However, despite any similarities, the regime introduced by the DPA 1998 differs markedly from the previous legislation in key respects:

- paper data: the DPA 1998 extends to cover manual personal data (ie, in paper or microfiche form), but only where it is part of a 'relevant filing system', structured so particular data can be readily found ${ }^{18}$

- sensitive personal data: this kind of information about an individual, falling within one or more 'delicate' categories, can only be lawfully processed if additional requirements are met (such as obtaining the 'explicit consent' of the individual concerned) ${ }^{19}$

- data security: written contracts and monitoring procedures governing data security will be required where a 'data controller' has personal data processed by a third party ${ }^{20}$

- notification: the triennial process of registering as a 'data user' with the Data Protection Registrar under the DPA 1984 is replaced by an annual process of 'notification' to the Data Protection Commissioner as a 'data controller' ${ }^{21}$

- rights of access: individuals have increased rights of access to their personal data (in particular, to manual personal data held in a relevant filing system, and to know the source of any personal data) ${ }^{22}$

- transfers outside the European Economic Area ('EEA'): ${ }^{23}$ the eighth data protection principle prohibits the transfer of personal data outside the EEA unless (broadly) the data subject consents $^{24}$ or the receiving country 'ensures an adequate level of protection for the rights and freedoms of data subjects in relation to the processing of personal data'. ${ }^{25}$

The DPA 1998 also provides for certain transitional relief to allow gradual compliance with the new regime. This is consistent with the Directive, which permitted Member States to provide extra compliance time in their national legislation for 'processing already under way'. ${ }^{26}$ Despite the fact that the exemptions are not at all easy to apply in practice, most pension schemes appear deliberately or unwittingly — to be relying on them, and postponing full compliance with the DPA 1998.

The first transitional period under the DPA 1998 runs from 24th October, 1998 to 23rd October, 2001; the second from 24th October, 2001 to $23 \mathrm{rd}$ October, 2007. During these periods, 'eligible data' — personal data 'subject to processing already underway immediately before' 24th October, $1998^{27}$ — is exempted from certain aspects of the 
DPA 1998. 'Eligible data' may be manual (in paper or microfiche form) or automated (which will cover a vast amount of personal data held, accessed, transferred or otherwise processed using computers, databases, e-mail or voicemail systems). ${ }^{28}$

There is little guidance in the DPA 1998 as to what will qualify as 'eligible data' in practice, but the key is probably to focus on the key attributes of the processing: such as the purposes of it, the categories of data and data subjects involved, and the processing systems being used. A material difference in any of these will probably be a change in processing sufficient to mean that the transitional exemptions no longer apply. ${ }^{29}$ Introducing a new data processing computer system, for example, may be a material change, whereas acquiring details of new members will probably not be (provided the kinds of personal data collected, the processing systems used, and the purposes for collecting the data, are unchanged). In many cases, only some data processing may benefit from a transitional exemption, and it may therefore be simpler and more cost-effective in practice to comply (voluntarily, at least in some respects) with the DPA 1998 from the outset. This is particularly so now, since only a few months remain at the first transitional period.

During the first transitional period, eligible manual personal data is exempt from all material aspects of the DPA 1998. Eligible automated data are exempt from certain significant aspects of the new Act until 24th October, 2001, ${ }^{30}$ including the provision of 'fair processing information' to data subjects, ${ }^{31}$ the need for consent and explicit consent for personal data processing $^{32}$ and the requirement of written contracts with data processors. ${ }^{33}$

Compliance with the other aspects of the DPA 1998 (such as the requirement to assess and monitor security systems of data processors) ${ }^{34}$ has been required since 1st March, 2000. Pension scheme trustees should therefore already be complying with these requirements even if they are relying on the transitional exemptions to postpone other compliance.

There is no second transitional period for eligible automated data. The latest date for compliance in relation to the processing of such data is therefore 23 October, 2001 (the end of the first transitional period). The exemptions applicable during the second transitional period are restricted in scope, and relevant only to eligible manual personal data which the trustees or their data processors physically 'held immediately before 24th October, 1998'. ${ }^{35}$

\section{Practical application of the DPA 1998}

The DPA 1998 is not an easy piece of legislation to apply in practice, especially in the pensions context where trustees are already subject to much other regulation. The final section of this paper, therefore, considers some practical pensions issues and how the DPA 1998 applies to them.

\section{Trustees' registration/notification}

All trustees should be covered by a pre-existing registration as a 'data user' under the DPA 1984, or have notified as a 'data controller' under the DPA 1998. No new data user registrations have been allowed since 1st March, 2000, but pre-existing registrations are being allowed to run their three-year course. When their old DPA 1984 registration expires, trustees will need to go through the new, annual notification procedure in the DPA $1998:^{36}$ this can be done either over the telephone or via the Internet. ${ }^{37}$ Processing personal data without a valid 
registration or notification in place is a strict liability criminal offence. ${ }^{38}$

\section{Paper-based personal data}

Various kinds of paper-based personal data may be held and used by trustees (or for them by their advisers), including scheme application forms, expression of wish forms, correspondence and trustee minutes. Such manual personal data will only be caught by the DPA 1998 if it is part of a 'relevant filing system'. This is defined in the DPA 1998 as:

'any set of information relating to individuals to the extent that, although the information is not processed by means of equipment operating automatically in response to instructions given for that purpose, the set is structured either by reference to individuals or by reference to criteria relating to individuals, in such a way that specific information relating to a particular individual is readily accessible. ${ }^{39}$

The Data Protection Commissioner has conceded that 'it is not wholly clear how this definition translates in practical terms in all conceivable situations'. ${ }^{40}$ However, the key elements appear to be: ${ }^{41}$

- that there is a set of paper-based information about individuals

- that there is a structure to this set either by reference to the individuals themselves, or by reference to criteria relating to them (eg, name or code number)

- that the structure works so that specific information about a particular individual is readily available.

It is difficult to lay down hard and fast rules as to how this definition will apply in practice since much will turn on the particular circumstances of each case. However, it is probably a reasonable starting point to say that paper-based personal data held within individual member files by pension scheme administrators will (at least, if the administrators are doing their job properly) often be part of a structured 'relevant filing system' and thus be caught by the DPA 1998. However, paper-based data held in less structured environments - such as on general documents or minutes files, or chronologically-ordered correspondence files which are not member-specific — will usually not be part of a relevant filing system, and will thus be exempt from the DPA 1998. Trustees should therefore be careful to ensure that any paper data that they would not want to disclose to a member seeking access are not stored on the member's individual file.

To the extent that paper-based data is part of a 'relevant filing system', the DPA 1998 will apply to it. Subject to any transitional exemptions, the processing of such paper data will have to comply with the DPA 1998, including the eight data protection principles,${ }^{42}$ and the data subject will be entitled to access to it. ${ }^{43}$

In many cases, however, it will be insufficient to consider only the position of paper personal data. This is because there will frequently be electronic copies of the paper data: personal data on application forms will be put onto a computer database, minutes and outgoing letters will frequently be prepared on a word processing system, and expression of wish forms and incoming correspondence may be electronically scanned. This process will convert the original paper-based information into automated personal data which, subject to any transitional exemptions available, ${ }^{44}$ will be caught by the DPA 1998 (regardless of the status of the original paper data). This is considered below in the context of expression of wish forms and trustee meeting minutes. 


\section{Expression of wish forms}

Under the DPA 1998, an expression of wish form is potentially personal data about the beneficiaries nominated in it, provided it sufficiently identifies them. ${ }^{45}$ It is suggested that, provided that the form is only ever kept in its paper format, is not placed on the member's individual file, and is kept in a sealed envelope until it is needed, ${ }^{46}$ it is unlikely to be caught by the DPA 1998 (at least until the member in question dies). This is because the form will probably not be part of a 'relevant filing system' in relation to the nominated beneficiaries. It will normally be filed by reference to the name of the member, and storing it in this way will not tend to make 'readily accessible' the specific information in it about the beneficiaries.

Some administrators are, however, scanning expression of wish forms onto their computer databases. This process will create an electronic copy of the paper-based personal data about the nominated beneficiaries, which will be caught by the DPA 1998 regardless of whether there is a 'relevant filing system'. Scanning an expression of wish form will also make it a great deal more difficult to metaphorically 'seal the envelope' and thereby hide the personal data about the named beneficiaries until the member's death. This may make it difficult for trustees to resist disclosing an electronic expression of wish form following an application by a data subject under section 7 of the DPA 1998 for access to his or her personal data. ${ }^{47}$

\section{Trustee meeting minutes}

Much of the analysis above also applies to trustee meeting minutes. If minutes exist solely in paper form, then the likelihood is that they will not constitute personal data. This is because - on the assumption they are kept in a distinct trustee minute book or file - they are unlikely to be part of a relevant filing system. The position is much less clear where (as will frequently be the case) the minutes are prepared on a computer or word-processing system, and electronic copies therefore also exist. In this case, the computer file(s) containing the minutes will constitute personal data about any member or other individual sufficiently identified in them. On this analysis, it is difficult to see how, strictly, trustees could avoid having to disclose the relevant section(s) of minutes in response to a section 7 data subject access request. Transitional exemptions might assist, but, as regards minutes of meetings since 24th October, 1998, these will last only until 23rd October, 2001 at latest. $^{48}$

Clearly, this has potentially significant implications for trustees and may require them to disclose minutes recording difficult and sometimes delicate decisions, where this might not have been required at common law. ${ }^{49}$ It is difficult to think of an easy way of resolving this problem. Deleting all the computer-based copies of the minutes is impractical. Similarly, disclosing only the bare minimum of information in the minutes (for example, just the individual's name) will probably not help. Apart from going against the spirit of the DPA 1998 and the Human Rights Act, the definition of 'personal data' expressly includes 'any expression of opinion about the individual and any indication of the intentions of the data controller or any other person in respect of the individual'. ${ }^{50}$ Proper minutes of difficult decisions about members may well involve one or both of these elements, which will then become disclosable as personal data. The alternative approach of recording only the bald decision in 
the minutes might avoid data protection problems, but could expose the trustees to allegations of breach of trust, maladministration or both. ${ }^{51}$

These are clearly areas where the strict requirements of the DPA 1998 do not sit easily with - and, in some cases, may directly conflict with - the other obligations on trustees. The Home Office undertook a general review of the DPA in late 2000 (inviting comments on the immediate effect of the new regime) and it is to be hoped that these areas were considered. ${ }^{52}$ In the meantime, the only sensible advice for trustees is that they should be ready for section 7 subject access requests, but should exercise caution as regards the disclosure of highly sensitive documents (such as expression of wish forms and trustee meeting minutes).

\section{Seventh principle contracts with data processors}

Trustees and other data controllers are required by the seventh data protection principle to take 'appropriate technical and organisational measures' to protect against the 'unauthorised or unlawful processing of personal data and against accidental loss or destruction of, or damage to, personal data'. ${ }^{53}$

Where trustees use a third party to carry out data processing functions for them, then (subject to any transitional exemptions which apply) the trustees must:

- choose a data controller offering 'sufficient' guarantees as regards security measures

- take 'reasonable steps' to ensure the data processor complies with those guarantees (ie have a monitoring policy and implement this at regular intervals or more urgently if the need arises)
- put in place a written contract which imposes obligations on the data processor equivalent to those imposed by the seventh principle on the data controller, and under which the data processor must act only on instructions from the data controller. ${ }^{54}$

The DPA 1998 provides only limited guidance on how to assess 'sufficiency' and 'reasonableness', ${ }^{55}$ although there is other, useful published guidance. ${ }^{56}$ In general, the acceptability of the measures adopted by trustees (and their data processors) will depend upon how sensitive the data is, and the implementation costs. As sophisticated computer technology develops to provide cost-effective protection systems for automated data, so trustees (and their data processors) will be expected to use them.

\section{Fair and lawful processing: Consent issues}

Subject to any transitional exemptions, the first data protection principle requires all processing of personal data to be fair and lawful. In broad terms, this requires that:

— the data subject is provided with certain 'fair processing information' (consisting of the identity of the trustees as the data controller, and the purpose or purposes for which his personal data are to be processed) ${ }^{57}$

- AND (in relation to the processing of non-sensitive personal data) that the consent of the data subject is obtained (or another of the conditions in Schedule 2 of the DPA 1998 is met)

- AND (in relation to the processing of sensitive personal data) that the explicit consent of the data subject is obtained $^{58}$ (or another of the conditions in Schedule 3 is met). 
There is no space to examine this issue in detail here, but it is suggested that pension scheme trustees should always seek to obtain requisite consent as a preferred way of complying with Schedules 2 and/or 3 of the DPA $1998 .^{59}$

In relation to new members, best practice must be for trustees to amend joining forms and other paperwork to incorporate an explicit consent clause (to cover the processing of both sensitive and normal personal data) to be signed by new members as they join the scheme. This should also incorporate the required 'fair processing information'.

For existing members, obtaining express consent will be more time consuming and costly. For non-sensitive personal data, it is suggested that inferred consent will suffice since it is not practically possible for an individual to be a member of, or beneficiary under, a pension scheme without the trustees processing personal data about him. ${ }^{60}$ However, it is probably wise to lay an 'audit trail' flagging the issue up to existing members in the next announcement, and the scheme booklet. This also provides an opportunity to ensure that the consent is specific and informed, and that the fair processing information is provided by 24 th October, 2001 at latest. ${ }^{61}$

Inferred consent will not suffice to render fair and lawful the processing of sensitive personal data, since, subject to any transitional exemptions which apply, the data subject's explicit consent is generally required in these circumstances. One limited and specific exemption from this requirement applies to sensitive personal data which was already being processed immediately before 1st March, 2000 , where that processing was necessary to establish or administer an occupational pension scheme. ${ }^{62}$ This concession will assist occupational scheme trustees with, for example, old ill health data about members which they need to retain (for example, because the ill health early retirements they granted on the back of them are reviewable under their deed and rules). The trustees will be exempt from the need to seek explicit consent from the individuals concerned to continue to hold the data.

In relation to sensitive personal data which was not being processing at 1 st March, 2000, or was being processed but not where this was 'necessary' to the establishment or running of an occupational scheme, trustees will need to obtain explicit consent. Any existing member now providing sensitive personal data (for example, on an ill health early retirement application) should therefore be asked to give his explicit consent at the time the data is provided.

\section{Conclusions}

It will be much more difficult for pension schemes to ignore data protection compliance issues under the DPA 1998 than it was under the DPA 1984. Trustees also need to be ready in case disgruntled beneficiaries seek to use the new legislation to access previously unavailable information, and to challenge trustee decisions. In some areas, compliance with the new regime will be little more than existing best practice. Where new procedures are necessary, this paper has sought to flag up how trustees may be able to prepare for the practical impact of the DPA 1998 by planning ahead.

\section{References}

1 This link doubtless owes something to the fact that the Council of Europe (the author of the Human Rights Convention) was also responsible for drafting what was arguably the first European data protection code: Treaty 108 - the Convention for the 
Protection of Individuals with Regard to Automatic Processing of Personal Data.

2 The Human Rights Act 1998 (Commencement No. 2) Order 2000 (2000 SI 1851).

3 Under the DPA 1984, enforcement action was only possible against registered data users. Many pension scheme trustees and managers (probably wrongly) did not register at all, with the result that the only sanction enforceable against them was a criminal prosecution for non-registration under s.5(1). The new regime under the DPA 1998 is enforceable against data controllers regardless of whether they have gone through the new notification procedure.

4 See The Data Protection Act 1998: An Introduction (The Office of the Data Protection Registrar [as she then was]: October 1998), p. 1: 'there is no room for complacency ... there is no excuse for non compliance and I shall be prepared to enforce vigorously'. Since it was brought into force 30 th January, 2001, the Commissioner is also responsible for implementing the Freedom of Information Act 2000.

5 These include prosecuting data controllers who process personal data without having gone through the proper notification or registration procedures (DPA 1998, ss.17, 20, 21), issuing enforcement notices (where data controllers are processing personal data in contravention of the DPA 1998: s.40) and issuing information notices (where the Commissioner needs to gather information on suspected breaches of the legislation: DPA 1998, s.43).

6 The most likely Convention rights to be raised in this context are the rights to respect for private life (article 8) and to freedom of expression (article 10). It is open to debate whether pension scheme trustees are 'public authorities' caught by the Human Rights Act. On one analysis, they are, since they discharge a quasi-public 'social welfare' function which the State would otherwise have to step in to provide; on the other, trustees of purely 'private sector' pension schemes may be said to play no public role. However, even if this latter analysis is correct, the courts and tribunals that will have to adjudicate on disputes between data subjects and pension scheme trustees on data protection and human rights issues are public authorities (see Human Rights Act, s.6(3)). As such, they must interpret primary and secondary domestic legislation, so far as it is possible to do so, in a way which is compatible with rights under the Human Rights Convention (s.3). It seems to follow that pension scheme trustees will therefore be affected whether directly or indirectly) by the Human Rights Act when considering data protection (and many other) issues.

71996 SI 1655.

8 See Re Londonderry's Settlement [1965] Ch 918; Wilson v Law Debenture Corporation plc [1995] OPLR 103.

9 Data subjects may now have access to paper-based personal data, and are entitled to know the source of any personal data (DPA 1998 s.7(1)(c)). Data subjects who feel that they are being affected by processing can request the Commissioner under DPA 1998, s.42 to undertake an 'assessment' of whether the processing is compliant with the DPA. The results of this is may, in turn lead the Commissioner to take other enforcement action (such as issuing information and/or enforcement notices).

10 The Commissioner ran an advertising campaign on television and posters on London Underground during the period 14-31st August, 2000, with the express aim of 'empowering the individual to use the law to protect their [sic] information' (Commissioner's website: www.dataprotection.gov.uk).

11 DPA 1998, s.1(1).

12 DPA 1998, s.2. The other categories are (broadly) information concerning the individual's racial or ethnic origin, political opinions, religious beliefs, trade union membership, criminal record and court proceedings.

13 DPA 1998, s.1(1).

14 DPA 1998, s.1(1).

15 DPA 1998, s.1(1).

16 DPA 1998, s.1(1).

17 The eight principles are set out in the Appendix to this paper.

18 See DPA 1998, s.1(1).

19 See DPA 1998, s.2, and the first data protection principle: DPA 1998, Schs.1 and 3.

20 See the seventh data protection principle: DPA 1998, Sch.1.

21 See DPA 1998, Part III, although registrations still current as at 1 March 2000 are being allowed to run their course; Freedom of Information Act 2000, Sch. 6, para. 8 .

22 See generally DPA 1998, Part II.

23 The fifteen EU member states, and also Norway, Iceland and Liechtenstein.

24 DPA 1998, Sch.4, para.1.

25 DPA 1998, Sch.1, para.13. A finding by the European Commission in accordance with the Directive, Arts.25 and 31 that a country outside the EEA does, or does not, ensure an 'adequate' level of protection is binding and conclusive, although to date, the Commission has only found in favour of Hungary and Switzerland. US organisations which sign up to the 'safe harbour' principles agreed between the EU and USA with effect from 1st November, 2000 will also be deemed to be recipients satisfying the eighth data protection principle.

26 Directive, Article 32.2.

27 DPA 1998, Sch.8, para.1.

28 See DPA 1998, s.1(1)(a): data which 'is being processed by means of equipment operating automatically in response to instructions given for that purpose'.

29 See Jay and Hamilton, Data Protection Law and Practice (London: Sweet \& Maxwell, 1999), pp. 
341-344: In general terms, 'the more the processing differs from that undertaken as at 24 October 1998, the less likely it is the transitional relief will be available' (p. 343); Commissioner's Introduction, pp. 27-28.

30 DPA 1998, Sch.8, para.13.

31 DPA 1998, Sch.1, para..2.

32 DPA 1998, Sch.2, para.1 and Sch.3, para.1.

33 DPA 1998, Sch.1, para.12.

34 DPA 1998, Sch.1, para.11(b).

35 DPA 1998, Sch.8, para.14.

36 See DPA 1998, Part III; The Data Protection (Notification and Notification Fees) Regulations 2000 (2000 SI 188); Notification Handbook: A complete guide to notification (The Office of the Data Protection Commissioner: February 2000).

37 See the Commissioner's Notification Handbook.

38 DPA 1998, ss.17(1) and 20(1). Trustees and other data controllers who process only manual personal data are technically exempt from the requirement to notify: DPA 1998, s.17(2). However, given that automated personal data is so expansively defined (see DPA 1998, s.1(1)(a): it will include, eg, personal data contained in e-mail messages, word-processed documents and voicemail systems) this exemption is extremely unlikely to apply in practice, and should not be relied on.

39 DPA 1998, s.1(1).

40 See the Commissioner's Introduction, p. 3.

41 This analysis is taken from the Commissioner's Introduction: p. 4.

42 Trustees will be required, for example, to process the data fairly and lawfully and only for specified purposes, keep it up to date, not keep it for longer than necessary, and store it securely: see the first, second, fourth, fifth and seventh data protection principles, respectively, in the Appendix.

43 DPA 1998, s.7.

44 The electronic personal data resulting from the conversion process may well not benefit from a transitional exemption during the first period since it will now be being held and otherwise processed in materially different way.

45 But not the member once he has died, since he is no longer a living individual.

46 The Commissioner's Office has expressed doubts in correspondence with us whether sealing the envelope will necessarily mean that the trustees do not process the personal data within it, although it is alive to the 'political' difficulties this raises.

47 They would, however, need to ensure, if disclosing the form to one data subject, that that they had removed references to any of the other nominated beneficiaries individuals: DPA 1998, ss.7(4); (5). Data controllers have 40 days to respond to a data subject access request: DPA 1998, ss.7(8), (10). The Commissioner's Office has indicated to us in correspondence that it is alive to the practical difficulties here. This may have been one aspect of the DPA 1998 which was reconsidered by the Home Office when it reviewed the legislation last year. See ref. 52 below.
48 Since exemptions during the second transitional period apply only to paper data which was physically held by the trustees as at 24 th October, 1998.

49 Because the minutes would reveal an exercise of the trustees' discretion: see Re Londonderry's Settlement [1965] Ch 918; Wilson v Law Debenture Corporation plc [1995] OPLR 103.

50 DPA 1998, s.1(1).

51 Since they would have no way of showing they had considered all the relevant issues, disregarded all the irrelevant ones, and generally applied themselves in accordance with trusts law and their deed and rules: see generally Edge v Pensions Ombudsman [1999] 4 All ER 546.

52 The author's understanding is that the results of this review are to be published during 2001 on the Home Office and/or Commissioner's websites: www.homeoffice.gov.uk; www.dataprotection.gov.uk 53 DPA 1998, Sch.1; see the Appendix.

54 DPA 1998, Sch.1, Sch.2, paras.11 and 12.

55 See DPA 1998, Sch.1, Part II, para.9.

56 See, eg, Data Protection Registrar, Guidelines (4th series: September 1997), pp. 66-69 (on the seventh (security) principle under the DPA 1984); Jay and Hamilton, Data Protection, pp. 71-73.

57 See DPA 1998 Sch. 1, Part II, paras. 1-4.

58 The Commissioner has said this should be 'absolutely clear' and include 'in appropriate cases', the specific detail of the processing, the particular types of data to be processed, the purposes of the processing and any special aspects of the processing which may affect the individual: Commissioner, Introduction, p. 11.

59 Certain other conditions may be useful as 'backstops' in the pensions context: eg Sch.2, condition 2 (the processing is necessary for the performance of a contract to which the data subject is a party, or to take steps at the data subject's request to enter into such a contract) may be useful in relation to establishing an annuity or buy out contract for a member; Sch.2, condition 3 (the processing is necessary to comply with any legal obligation) may cover much trustee activity where consent cannot be obtained; Sch.3, condition 6 (the processing is necessary in connection with legal proceedings or to obtain legal advice) may assist trustees seeking advice on, say, a contentious ill health early retirement.

60 Although the Commissioner's view (based on the Directive, Arts.2(h) and 7(a)) appears to be that consent requires some active signification of agreement by data subjects (see the Introduction, p. 10 c.f. p. 11), the fact that explicit consent is required for sensitive personal data suggests that something less will suffice for 'normal' data.

61 Where no transitional exemption applies, the 'fair processing information' should strictly have been issued to data subjects by 1st March, 2000.

62 See the Data Protection (Processing of Sensitive Personal Data) Regulations 2000 (2000 SI 417), reg.6. 


\section{APPENDIX 1 THE DATA PROTECTION PRINCIPLES}

1 Personal data shall be processed fairly and lawfully and, in particular, shall not be processed unless:

(a) at least one of the conditions in Schedule 2 is met, and

(b) in the case of sensitive personal data, at least one of the conditions in Schedule 3 is also met.

2 Personal data shall be obtained only for one or more specified and lawful purposes, and shall not be further processed in any manner incompatible with that purpose or those purposes.

3 Personal data shall be adequate, relevant and not excessive in relation to the purpose or purposes for which they are processed.

4 Personal data shall be accurate and, where necessary, kept up to date.
5 Personal data processed for any purpose or purposes shall not be kept for longer than is necessary for that purpose or those purposes.

6 Personal data shall be processed in accordance with the rights of data subjects under this Act.

7 Appropriate technical and organisational measures shall be taken against unauthorised or unlawful processing of personal data and against accidental loss or destruction of, or damage to, personal data.

8 Personal data shall not be transferred to a country or territory outside the European Economic Area unless that country or territory ensures an adequate level of protection for the rights and freedoms of data subjects in relation to the processing of personal data.

(C)François Barker 